\title{
OS CAMINHOS DA EXPANSÃO DA EDUCAÇÃO SUPERIOR NO BRASIL E EM PORTUGAL: CONVERGÊNCIAS E DIVERGÊNCIAS
}

\author{
THE PATHWAYS OF THE EXPANSION OF HIGHER EDUCATION IN BRAZIL AND \\ PORTUGAL: CONVERGENCES AND DIVERGENCES
}

\author{
LAS FORMAS DE AMPLIACIÓN DE EDUCACIÓN SUPERIOR EN BRASIL Y \\ PORTUGAL: CONVERGENCIAS Y DIVERGENCIAS
}

\author{
(iD) Belmiro Gil Cabrito \\ Doutor em Ciências da Educação \\ Instituto de Educação da Universidade de Lisboa (IEUL) \\ Lisboa/Portugal \\ b.cabrito@ie.ulisboa.pt \\ Alda Maria Duarte Araújo Castro \\ Doutora em Educação \\ Universidade Federal do Rio Grande do Norte \\ Rio Grande do Norte/Brasil \\ aldacastro01@hotmail.com
}

\begin{abstract}
Resumo: O artigo analisa a expansão da educação superior no Brasil e em Portugal procurando identificar as convergências e as divergências ocorridas em consequência das políticas de adotadas em cada país para aumentar a cobertura por esse nível de ensino. O texto toma como pressuposto que a necessidade de ampliação por educação superior ocorre no contexto das transformações econômicas e sociais das últimas décadas do século XX e princípios do XXI, bem como que tal ampliação trouxe o estabelecimento de novos padrões de competitividade, o uso intensivo das tecnologias da comunicação e da informação - o que provocou a inversão da concepção de Estado que até então era prevalente na organização da sociedade capitalista. Os dados coletados tiveram como referência, no Brasil, as sinopses estatísticas elaboradas pelo INEP, sobre a educação superior e, em Portugal, a Base de Dados Portugal Contemporâneo (PORDATA). Internacionalmente, utilizou-se dados da World Conference of Higher Education (UNESCO). Os resultados evidenciam que a expansão da educação superior ocorreu nos dois países, mas guarda entre si diferenças significativas de cunho econômico, social e político assentadas em condições históricas, as quais foram determinadas pela posição que os países ocupam dentro do capitalismo global.
\end{abstract}

Palavras-chave: Educação superior. Expansão do Ensino superior. Políticas educacionais.

\begin{abstract}
The article analyzes the expansion of higher education in Brazil and Portugal seeking to identify the convergences and divergences that have occurred as a consequence of the policies adopted in each country to increase coverage by this level of education. The article assumes that the need for expansion by higher education occurs in the context of the economic and social transformations of the last decades of the twentieth and beginnings of century twenty-first, which led to the establishment of new standards of competitiveness, the intensive use of communication and information technologies that provoked the inversion of the concept of State that until then was prevalent in the organization of the capitalist society. The collection data had as reference, in Brazil, the Synopsis Statistics elaborated by INEP, on higher education and, in Portugal, the Database Portugal Contemporary (PORDATA). Internationally, data from the World Conference of Higher Education (UNESCO) were used too. The results show that the expansion of higher education took place in both countries, but it preserves significant economic, social and political differences among them, and they are based on historical conditions, which were determined by the position that the countries occupy within global capitalism.
\end{abstract}

Keywords: Higher education. Higher education expansion. Educational policies.

Resumen: El artículo analiza la expansión de la educación superior en Brasil y Portugal buscando identificar las convergencias y divergencias que se han producido como resultado de las políticas de expansión adoptadas en cada país para aumentar la cobertura de este nivel de educación. En el contexto de las transformaciones económicas y sociales de las últimas décadas del siglo XX y principios del XXI, que trae el establecimiento de nuevos patrones de competitividad, el uso intensivo de las tecnologías de la comunicación, provocó la inversión de la concepción de Estado que hasta entonces era prevalente en la organización de la sociedad capitalista. Los datos colectados se basaron en Brasil, en las estadísticas preparados por el INEP, en educación superior y en Portugal, en la base de datos Portugal contemporáneo (PORDATA). Internacionalmente, se utilizaron datos de la World Conference of Higher Education (UNESCO). Los resultados evidencian que la expansión de la educación superior ocurrió en los dos países, pero guarda entre sí, diferencias significativas de cuño económico, social y político y están asentadas en condiciones históricas, las cuales, fueron determinadas por la posición que los países ocupan dentro del capitalismo global.

Palabras clave: Políticas educativas. Educación universitaria. Expansión de la enseñanza superior.

Para citar - (ABNT NBR 6023:2018)

CABRITO, Belmiro Gil; CASTRO, Alda Maria Duarte Araújo. Os caminhos da expansão da educação superior no Brasil e em Portugal: convergências e divergências. Eccos - Revista Científica, São Paulo, n. 56, p. 1-22, e11156, jan./mar. 2021. Disponível em: https://doi.org/10.5585/eccos.n56.11156. 


\section{Os caminhos da expansão da educação superior no Brasil e em Portugal: convergências e divergências}

O artigo analisa a expansão da educação superior no Brasil e em Portugal, procurando identificar as convergências e as divergências ocorridas em consequência das políticas de expansão adotadas em cada país para aumentar a cobertura por esse nível de ensino. O artigo tem como pressuposto a necessidade de ampliar a educação superior no contexto das transformações econômicas e sociais, ocorridas nas últimas décadas do século XX e XXI, que ocasionaram o estabelecimento de novos padrões de competitividade, o uso intensivo das tecnologias da comunicação e da informação, bem como provocaram a inversão da concepção de Estado que, até então, era prevalente na organização da sociedade capitalista. Convém salientar que a expansão da educação superior, ocorrida nos dois países, guarda, entre si, diferenças significativas de cunho econômico, social e político e estão assentadas em condições históricas, determinadas pela posição que os países ocupam dentro do capitalismo global.

Para discutir a temática, o artigo foi estruturado em três seções: a primeira trata da centralidade que os sistemas de educação superior assumem no contexto de transformação produtiva, no qual o conhecimento passa a ser entendido como fator de desenvolvimento econômico e de inserção dos países no mundo globalizado. A segunda analisa as principais estratégias utilizadas pelos governos de Brasil e Portugal para expandir a educação superior, enfatizando a sua articulação com as tendências globais. A terceira apresenta alguns indicadores da expansão do ensino superior Brasil/Portugal, adotando, com parâmetro, a evolução dos sistemas públicos e privados, o número de vagas/candidatos, como também a distribuição por gênero, matrículas e organização acadêmica. Por fim, apresenta algumas convergências e divergências que têm acompanhado a expansão desse nível de ensino nos dois países.

\section{A centralidade dos sistemas da educação superior para as estratégias nacionais no mercado global}

Nas últimas décadas, o paradigma tecnológico, intensivo de conhecimento trouxe para as instituições de educação superior novos desafios, colocando-as no centro do debate e das agendas das políticas governamentais. A educação, no contexto da globalização, passou a ser vista, em muitas partes do mundo, como um motor para o desenvolvimento de uma economia baseada no conhecimento. Nesse sentido, pode-se afirmar que a centralidade do conhecimento 
na sociedade atual impacta, diretamente, as demandas globais e locais para a educação superior. Para Castells (1999), o conhecimento e a informação sempre foram elementos fundamentais para o crescimento da economia e, na atualidade, a evolução da tecnologia tem determinado cada vez mais a capacidade produtiva dos países e os padrões de vida das sociedades contemporâneas. Esse também é o entendimento de Carnoy (1995) para quem o incremento da produtividade e o crescimento econômico dependem cada vez mais da aplicação do conhecimento e da informação à produção, tornando, assim, a base científica cada vez mais importante. Esses aspectos tornam-se elementos centrais da competitividade dos países e elementos fundamentais para a sua inserção no mundo globalizado.

Nesse cenário global, as políticas públicas, principalmente a política educacional, têm sofrido modificações considerando que existe uma indissociável relação entre a educação e o modo de produção capitalista, reconfigurado em cada tempo histórico, assumindo a educação, como se referia Althusser (1980), a natureza de um aparelho ideológico do Estado. Mundialmente, a educação superior passou a assumir novas demandas com o objetivo de promover e desenvolver as competências necessárias ao mundo do trabalho. Como espaço de produção do conhecimento, a educação superior tem hoje a difícil tarefa de preparar o indivíduo para um mundo globalizado, sem fronteiras e centrado no conhecimento.

Considerada um dos fatores decisivos para o desenvolvimento, não causa estranheza a crescente centralidade da educação para as estratégias nacionais no mercado global. No quadro da educação e da globalização, o nível de exigência que se coloca a indivíduos e países explica o quanto é crucial o ensino superior e, correlativamente, a necessidade de investir em novas tecnologias e processos. Desse modo, se explicam algumas das dimensões que caracterizam o ensino superior na atualidade e evidenciam as suas principais tendências, nomeadamente nos países desenvolvidos e em desenvolvimento como o crescimento acelerado das matrículas, denotando um processo de massificação e de universalização da educação superior; o alargamento da idade escolar numa perspetiva de formação ao longo da vida, assistindo-se ao aumento continuado do número de indivíduos portadores de graus dos $2^{\circ}$ e $3^{\circ}$ ciclos, como, por exemplo em Portugal; a diversificação das ofertas educativas, seja pela variedade dos campos de estudo seja pela diversidade das instituições de ensino superior num processo de resposta às necessidades identificadas no mercado de trabalho; aumento do ensino superior a distância, como no caso do Brasil; privatização desse grau de ensino por via do financiamento privado de instituições públicas e da sua oferta por instituições privadas 
com fins lucrativos; tendência para a diminuição da cohorte dos graduados do ensino secundário, como acontece, atualmente, na Europa e nos Estados Unidos da América.

Nesse cenário, novas diretrizes estão postas para o ensino superior, elaboradas por políticas nacionais e supranacionais, nas quais os organismos internacionais desempenharam um papel importante na sua disseminação. Existe, na atualidade, um conjunto de documentos produzidos e que circulam nos fóruns de decisões, considerados pelos responsáveis pela formulação de políticas educacionais como "obrigatórios" ou que "legitimam" as diretrizes para que os estados nacionais possam definir suas politicas educativas. Na operacionalização dessas orientações transnacionais, os organismos internacionais como o Banco Mundial, a Organização para Cooperação e o Desenvolvimento Econômico, a Organização Mundial de Comércio e a Organização das Nações Unidas para a Educação, a Ciência e a Cultura, elaboraram uma agenda de orientação para que os países pudessem ajustar suas políticas de educação.

Levando em consideração as conclusões da World Conference of Higher Education (2009) e os dados do Institute of Statistics da Unesco (2017), globalmente, a percentagem de taxa líquida de matrículas, no ensino superior, cresceu de 19\% em 2000 para 26\% em 2007, com ganhos expressivos para os países desenvolvidos. Existem cerca de 150,6 milhões de estudantes do terceiro ciclo no mundo, representando um aumento de, aproximadamente, $53 \%$ em relação a 2000. Nos Estados Unidos da América, assiste-se a um ensino superior em massa, com uma taxa real de educação superior em torno dos 40\%, desde a década de 1960 . A Europa Ocidental e o Japão experimentaram um rápido crescimento nos anos de 1980, seguido dos países da Ásia Oriental e da América Latina. A China e a Índia, atualmente o maior e o terceiro maior sistema acadêmico do mundo, têm crescido rapidamente e continuarão a fazê-lo. Os países em desenvolvimento ainda educam menos de $10 \%$ da faixa etária de 18 a 24 anos, tendo, nos países de baixo rendimento, a participação no nível terciário melhorado apenas marginalmente de 5\% em 2000 para 7\% em 2007, sendo a África Subsaariana a região com a taxa de participação mais baixa do mundo (5\%). Na América Latina, a taxa real de educação superior é ainda muito pequena, embora tenha havido uma expansão significativa nos últimos anos.

Esse fenômeno tem levado à massificação do ensino superior no sentido atribuído por Martin Trow ao fenômeno (1973), termo que, segundo Almeida et al. (2012), está frequentemente associado à democratização do acesso ao ensino superior por parte de alunos oriundos das camadas sociais e culturais menos favorecidas e com menor tradição familiar de 
formação acadêmica superior. Segundo dados do World Conference on Higher Education (2009), a tendência para a massificação aumentará nos próximos anos, embora os países não se situem no mesmo patamar de atendimento. É alarmante a diferença entre os países desenvolvidos e em desenvolvimento no atendimento à educação superior como se pode verificar na Tabela 1, cujos dados se pretendem meramente ilustrativos do exposto.

Tabela 1 - Taxa bruta de escolarização do ensino superior no mundo, no período de 1999 a 2013

\begin{tabular}{c|c|c|c|c|c|c|c|c|c}
\hline Anos & Argentina & Brasil & Chile & França & Itália & Portugal & China & EUA & México \\
\hline $\mathbf{1 9 9 9}$ & $48 \%$ & $16 \%$ & $37 \%$ & $54 \%$ & $48 \%$ & $45 \%$ & $7 \%$ & $72 \%$ & $18 \%$ \\
\hline $\mathbf{2 0 1 3}$ & $80 \%$ & $46 \%$ & $84 \%$ & $62 \%$ & $63 \%$ & $66 \%$ & $30 \%$ & $89 \%$ & $29 \%$ \\
\hline
\end{tabular}

Fonte: Elaborado pelos autores. Institute of Statistics Education. Unesco, 2017.

Os dados evidenciam que os países, de forma geral, se preocuparam em desenvolver políticas que possibilitassem a expansão dos seus sistemas de ensino superior, permitindo perceber a natureza global do crescimento da procura de ensino superior. A Tabela 1 permite verificar que houve um crescimento da taxa bruta em diferentes países. No que diz respeito a Portugal e ao Brasil, pode-se concluir que ambos os países registraram um forte crescimento nesse nível de ensino nos últimos 20 anos, sendo que o incremento relativo no Brasil foi mais forte do que em Portugal, ainda que este mantenha a taxa bruta de escolarização no ensino superior maior do que a registrada no Brasil. Os dados mostram que a taxa bruta de escolarização do ensino superior no Brasil (no período de 1999 a 2013) cresceu 30\%, chegando em 2013 a um atendimento de 46\%. Em Portugal, em 1999, já se registrava um percentual de atendimento de 45\%, ou seja, 14 anos antes o País já se encontrava em um patamar que somente agora começa a ser vislumbrado no Brasil. Em 2013, Portugal atingiu a taxa bruta de escolarização de ensino superior de $66 \%$ o que demonstra que houve um grande esforço registrado por aquele país que, no período, teve aumentada a sua taxa em $21 \%$.

Os dados confirmam que, dessa forma, seguindo a tendência global, tanto o Brasil quanto Portugal procuram encontrar estratégias para atender a essa nova exigência de qualificação provocada pelas novas demandas produtivas de qualificação em nível superior de sua população. No entanto, é preciso considerar que os governos nacionais adotaram estratégias diferenciadas com o objetivo de atender à expansão da educação superior. 


\section{Estratégias utilizadas pelos governos do Brasil e Portugal para expandir o educação superior}

O impacto da globalizaçãofoi determinante para que os países passassem a ajustar seus sistemas educativos às novas demandas da sociedade global. Para Carnoy (1995), existiram três tipos de reformas, com objetivos diferentes, que foram implementadas nos países considerando as condições políticas e econômicas de cada um: reformas "impulsionadas por motivos de competitividade”, a fim de adaptar os países às novas demandas da qualificação; reformas impulsionadas por "motivos financeiros", com cortes nos orçamentos do setor público e a participação de empresas privadas no financiamento da educação; reformas “impulsionadas por motivo de equidade", para melhorar o importante papel que a educação desempenha na mobilidade e na igualdade social.

As políticas implementadas no Brasil para a expansão do ensino superior contemplam os três tipos de reforma, no entanto, se enquadram, primordialmente, nas reformas impulsionadas por motivos financeiros e são cada vez mais cooptadas e dimensionadas por interesses políticos e econômicos geoestratégicos mais amplos. Pode-se, ainda, identificar que a política de expansão assenta-se em quatro principais pressupostos: uma necessária relação entre desenvolvimento socioeconômico e expansão do ensino superior; a posição de atraso que o Brasil ocupa no setor educativo em relação a países desenvolvidos; o crescimento dos egressos do ensino médio o que provoca uma demanda reprimida e a compreensão de que a educação superior é um direito de todos. Nesse contexto, o Brasil, nas últimas décadas, vem adotando um conjunto de estratégias que têm possibilitado a expansão significativa do ensino superior, representada pela crescente participação quer do setor público quer do privado com prevalência deste último - o que o caracteriza como de natureza quantitativa eempresarial em detrimento de uma educação democrática, universalizante e de qualidade.

Em Portugal, apesar de não ser tão fácil enquadrar a expansão do ensino superior num único tipo dos enunciados por Carnoy (1995), é possível, no entanto, identificar períodos e motivações de reforma no ensino superior nas últimas décadas. Indubitavelmente, a reforma do ensino superior nos anos imediatamente posteriores à Revolução Democrática de 1974 foi impulsionada pelos desejos de elevar o grau de equidade desse nível de ensino e garantir a todos o usufruto de um direito, bem como, pela compreensão do papel que esse nível educativo pode desempenhar no desenvolvimento social e econômico dos países. Todavia, a partir de 1986, as reformas na educação superior portuguesa enquadram-se nas reformas impostas por motivos financeiros nomeadamente em virtude de: a) abertura desse nível de 
ensino à iniciativa privada em 1986; b) a privatização progressiva do ensino superior público após 1992, com o estabelecimento de taxas de frequência nesse subsistema e cortes sucessivos no financiamento público das instituições públicas do ensino superior a que não é estranho, aliás, o Processo de Bolonha; c) a publicação do novo Regime Jurídico das instituições públicas de ensino superior (RJIES - Lei $n^{\circ}$ 62/2007 de 10 de setembro) que permite a sua passagem e fundação, e estabelece um Conselho Geral composto por elementos da Academia e da sociedade civil como órgão máximo de decisão.

\subsection{O caminho adotado pelo Brasil para a expansão da educação superior no período Pós- $L D B n^{\circ} 9.394 / 96$}

Nas últimas décadas, vem se verificando um processo crescente de expansão do ensino superior no Brasil. Segundo Cabral Neto e Castro (2014), isso ocorreu com o argumento de que esse nível educacional é de importância fundamental para a inserção do país no mundo globalizado, o que demandaria níveis mais elevados de qualificação profissional. Nesse contexto, o País vem experimentando um processo de expansão da educação superior, recortado por uma série de particularidades. A Lei de Diretrizes e Bases nº 9.394/96 (LDB) e os marcos normativos que lhe sucederam, assim como os programas governamentais de indução da expansão, favoreceram a organização de um "sistema" de educação superior, no entanto, contribuíram de forma tímida para o fortalecimento da educação como bem público. Ao contrário, favoreceu o desenvolvimento do setor privado que, usufruindo da flexibilização das normas e do uso dos recursos públicos, se ampliou de forma acentuada, tornando-se hegemônico no processo de expansão da educação superior.

Segundo autores que estudam a temática, entre eles, Cabral Neto e Castro (2014), Silva Júnior e Catani (2013), a expansão da educação pós-LDB ocorreu por uma série de iniciativas governamentais e pela atuação da iniciativa privada, com ênfase no setor mercantil. Quanto às iniciativas governamentais para a expansão no setor público, registra-se a aprovação do Programa de Apoio a Planos de Reestruturação e Expansão das Universidades Federais Brasileiras (REUNI), pelo Decreto $\mathrm{n}^{\circ}$ 6.096, de 24 de abril de 2007, que trouxe significativas mudanças para as universidades federais na medida em que teve como objetivo ampliar o acesso e a permanência na educação superior, no nível de graduação, por meio de um melhor aproveitamento dos recursos humanos existentes e da estrutura física, em uma perspectiva de racionalização dos recursos existentes. O referido Decreto, no seu artigo $2^{\circ}$, apresenta entre as suas principais diretrizes: a) a necessidade de aumentar as vagas de 
ingresso (sobretudo no período noturno), redução das taxas de evasão e a ocupação de vagas ociosas; b) a ampliação da mobilidade estudantil (circulação de estudantes entre instituições, cursos e programas); c) a revisão da estrutura acadêmica (reorganização dos cursos de graduação, atualização de metodologias, busca da elevação da qualidade); d) a diversificação das modalidades de graduação; e) a ampliação das políticas de inclusão e assistência estudantil; f) a articulação da graduação com a pós-graduação e da educação superior com a básica (BRASIL, 2007).

Um outro caminho adotado pelo governo brasileiro foi a utilização da educação a distância (EAD). Justifica-se essa estratégia tendo em vista que o desenvolvimento das tecnologias da comunicação possibilitou os baixos custos educativos, bem como o atendimento em tempo real, reduzindo as distâncias que separam alunos e professores. Nesse contexto, a educação a distância tem despontado como alternativa valiosa para a expansão do ensino superior, por suas potencialidades de atendimento a um grande contingente de alunos sem, contudo, exigir um grande investimento do Estado. A aprovação da LDB nº 9.394, em 1996, abriu inúmeras possibilidades para a expansão da modalidade da EAD, ao flexibilizar os procedimentos a serem adotados na criação e implementação de cursos de graduação e pósgraduação lato sensu. A utilização em larga escala da EAD para aumentar a cobertura da demanda por ensino superior é uma tendência recente que encontra respaldo nas orientações dos organismos internacionais e na LDB.

Por outro lado, o próprio governo cria seu sistema de educação a distância, por meio do Programa Universidade Aberta do Brasil (UAB), criada pelo Decreto $\mathrm{n}^{\circ}$ 5.800/2006. Nesse sistema, a institucionalização da educação a distância é necessária para redução das distorções regionais no acesso à graduação, sendo, segundo o argumento oficial, um instrumento de democratização desse nível de ensino a regiões diversas no Brasil.

Uma outra estratégia utilizada pelo Brasil para expandir o atendimento do ensino superior foi a privatização. O ensino superior brasileiro, desde a sua origem, contou com a participação da iniciativa privada na sua configuração. No entanto, na década de 1990, assistiu-se a uma crescente privatização desse grau de ensino, inclusive, com o apoio financeiro do governo a programas que favorecem a ampliação da iniciativa privada. Segundo Cabral Neto e Castro (2014), esse imbricamento entre o público e o privado, para atender às demandas por educação em nível superior, no Brasil, já vinha sendo reforçado desde 2004 com a aprovação da Lei $\mathrm{n}^{0}$ 11.079, de 30 de dezembro de 2004, que "institui normas gerais para licitação e contratação de parceria público-privada no âmbito da administração pública". 
Para Mancebo (2004), embora a privatização no campo da educação superior não seja um fato recente, tem sido impulsionada nas últimas décadas por fatores como a saída do Estado de seu necessário protagonismo na implementação da universidade como um bem público e direito de cidadania e do seu papel de mantenedor pleno dessa instituição social; assunção de uma gestão da educação superior nos moldes das empresas e a semiprivatização das próprias universidades públicas. Dessa forma, a privatização, resultante desse processo, indica uma transformação que concorre para que as instituições universitárias se tornem mais empresariais acatando as regras do mercado em detrimento de uma conduta acadêmica própria das IES.

Alguns indicadores são apresentados para demonstrar como foi se configurando a expansão do ensino superior no Brasil. Entre eles: a) a evolução do número de vagas e candidatos inscritos nos sistemas de ensino público e privado; b) a evolução do número de matriculados no ensino superior por sexo nas instituições públicas e privadas; c) a evolução do número de matrículas em cursos de graduação por organização acadêmica e rede administrativa.

Tabela 2 - Evolução do número de vagas e de candidatos inscritos ao Ensino Superior Presencial Público e Privado no Brasil de 2003 a 2015

\begin{tabular}{c|c|c|c|c|c|c}
\hline \multirow{2}{*}{ Ano } & \multicolumn{3}{|c|}{ Vagas oferecidas } & \multicolumn{3}{c}{ Candidatos inscritos } \\
\cline { 2 - 7 } & Pública & Privada & Total & Pública & Privada & Total \\
\hline $\mathbf{2 0 0 3}$ & 261.276 & 1.560 .968 & 1.822 .244 & 2.236 .670 & 2.343 .005 & 4.579 .675 \\
\hline $\mathbf{2 0 0 7}$ & 329.260 & 2.494 .682 & 2.823 .942 & 2.290 .490 & 2.901 .270 & 5.191 .760 \\
\hline $\mathbf{2 0 1 1}$ & 484.943 & 2.743 .728 & 3.228 .671 & 5.138 .136 & 4.028 .451 & 9.166 .587 \\
\hline $\mathbf{2 0 1 5}$ & 530.552 & 3.223 .732 & 3.754 .284 & 8.517 .232 & 5.508 .890 & 14.026 .122 \\
\hline $\boldsymbol{\Delta} \%$ & $103 \%$ & $106,5 \%$ & $106,2 \%$ & $280 \%$ & $135 \%$ & $206 \%$ \\
\hline
\end{tabular}

Fonte: Instituto Nacional de Estudos e Pesquisas Anísio Teixeira - Sinopse e Estatística do Ensino Superior.

A Tabela 2 permite visualizar como ocorreu a configuração da evolução do número de vagas e candidatos inscritos na educação superior no Brasil na modalidade presencial, nas redes públicas e privadas no período de 2003 a 2015. Considerando as duas redes administrativas, a oferta de vagas cresceu 106,2\% entre 2003 e 2015. Dessas vagas, o setor público, em 2003, ofereceu 261.276 enquanto o setor privado, 1.560.968. No ano de 2015, do total de vagas oferecidas, ou seja, 3.754.284, o setor público ofereceu 14,13\% o que corresponde a 530.552 vagas e o setor privado $85,87 \%$ correspondendo a 3.223 .732 matrículas, o que demonstra que, apesar do esforço governamental em aumentar o número de 
vagas no setor público, o setor privado continuou crescendo em maiores proporções, mantendo-se, portanto, quase inalterado o quadro de privatização da educação superior no país.

Quanto aos candidatos inscritos no ano de 2003, o setor público correspondeu a um total de 2.236.670 com 48,84\% das inscrições e o setor privado teve 2.343.005, correspondendo a 51,16\% do total das inscrições. Quando se compara o número de vagas com inscritos, pode-se verificar que a grande procura dos estudantes está na rede pública em uma relação de 8,56 candidatos por vaga; no setor privado, essa relação é de 1,5 candidato por vaga. Em 2015, foram inscritos, para concorrer a uma vaga no ensino superior, 14.026,122 candidatos. Destes, $8.517,232$ se inscreveram para concorrer a uma vaga no setor público (60,72\% das vagas oferecidas) o que correspondeu a uma relação de 16,05 candidatos por vagas. No setor privado, o número de inscrições foi de 5.508 .890 e a relação candidatos por vaga foi de apenas 1,7 o que comprova que o setor público ainda é a primeira escolha dos estudantes brasileiros apesar do grau de privatização que o sistema vem assumindo.

Dois programas governamentais se sobressaem no sentido de possibilitar a expansão dessas vagas. O primeiro, criado pela Lei ${ }^{\circ} 10.260$, de 12 de julho de 2001 , que dispõe sobre a criação do Fundo de Financiamento ao Estudante do Ensino Superior (FIES), de natureza contábil, o fundo é destinado à concessão de financiamento a estudantes regularmente matriculados em cursos superiores não gratuitos e com avaliação positiva nos processos conduzidos pelo Ministério da Educação, de acordo com regulamentação própria. Posteriormente, a Lei $\mathrm{n}^{\mathrm{o}}$ 12.513/2011 altera a lei de criação do FIES, ampliando a sua abrangência para beneficiar estudantes matriculados em cursos da educação profissional e tecnológica, bem como em programas de mestrado e doutorado com avaliação positiva.

O segundo Programa de financiamento às instituições privadas foi institucionalizado pela Lei $\mathrm{n}^{\circ} 11.906 / 05$ e concede bolsas de estudos, parciais ou integrais para os cursos de graduação pagos. Trata-se do Programa Universidade para Todos (Prouni); para Mancebo (2004), o programa está longe de corrigir a distribuição desigual dos bens educacionais; na maioria das vezes, a privatização promovida pelo programa, aprofunda as condições históricas das desigualdades sociais e da negação do direito à educação.

No que se refere à expansão das matrículas e a sua distribuição por gênero, a Tabela 3 permite fazer algumas análises. 
Tabela 3 - Evolução do número de matriculados no Educação Superior presencial por sexo nas instituições públicas e privadas no período de 2003 a 2015

\begin{tabular}{c|c|c|c|c|c|c|c}
\hline \multirow{2}{*}{ Ano } & Total no & \multicolumn{2}{|c|}{ Instituições Públicas } & \multicolumn{3}{c}{ Instituições Privadas } \\
\cline { 3 - 8 } & Brasil & Fem & Masc. & Total & Fem. & Masc. & Total \\
\hline $\mathbf{2 0 0 3}$ & 3.887 .022 & 625.951 & 510.419 & 1.136 .370 & 1.567 .295 & 1.183 .357 & 2.750 .652 \\
\hline $\mathbf{2 0 0 7}$ & 4.880 .381 & 650.801 & 590.167 & 1.240 .968 & 2.030 .177 & 1.609 .236 & 3.639 .413 \\
\hline $\mathbf{2 0 1 1}$ & 5.746 .762 & 836.857 & 758.534 & 1.595 .391 & 2.337 .249 & 1.814 .122 & 4.151 .371 \\
\hline $\mathbf{2 0 1 5}$ & 6.633 .545 & 955.316 & 868.436 & 1.823 .752 & 2.732 .055 & 2.077 .738 & 4.809 .793 \\
\hline $\mathbf{\Delta \%}$ & $70 \%$ & $52 \%$ & $70 \%$ & $60 \%$ & $74 \%$ & $75 \%$ & $74 \%$ \\
\hline
\end{tabular}

Fonte: Instituto Nacional de Estudos e Pesquisas Anísio Teixeira - Sinopse e Estatística do Ensino Superior.

O crescimento das matrículas, no período compreendido entre 2003 e 2015, foi da ordem de 70\%, passando de 3.887.022 em 2003 para 6.633.545 em 2015. Pode-se verificar, também, que o maior crescimento se dá na rede privada, com $74 \%$ das matrículas, enquanto na rede pública as matrículas cresceram 60\%. No ano de 2003, o setor público foi responsável por $29,24 \%$ das matrículas, enquanto o setor privado por $70,76 \%$. No ano de 2015 , a participação do setor público nas matrículas foi de $27,49 \%$ e do setor privado, de $72,51 \%$, o que demonstra um crescimento de sua participação na oferta do ensino superior no Brasil. A distribuição das matrículas por gênero evidencia que a presença feminina é majoritária tanto na rede pública quanto na rede privada. Em 2003, as mulheres representavam 55,08\% das matrículas na rede pública e os homens $44,91 \%$. Na rede privada, essa relação, no mesmo ano, era de 56,97\% de mulheres e 43,03\% de homens. No ano de 2015, essa relação, na rede pública, é de 52,38\% o que demonstra que há um decréscimo da participação feminina nas matrículas da rede publica. Na rede privada, as mulheres também são maioria e correspondem a $56,81 \%$ com um decréscimo insignificante e os homens $43,19 \%$. Ou seja, apesar de o número de jovens do gênero feminino haver crescido, há uma redução percentual da participação feminina nas duas redes.

Um outro indicador de grande relevância para se analisar a configuração do ensino superior no Brasil, diz respeito à distribuíção das suas matrículas pela organização acadêmica nas redes públicas e privadas. Conforme consta na tabela 04 . 
Tabela 4 - Número de matrículas em cursos de graduação por organização acadêmica e rede administrativa no período de 2003 a 2015

\begin{tabular}{|c|c|c|c|c|c|c|c|r|}
\hline \multirow{2}{*}{ ANO } & \multicolumn{2}{|c|}{ UNIVERS. } & \multicolumn{2}{c|}{$\begin{array}{c}\text { CENTROS } \\
\text { UNIVER. }\end{array}$} & \multicolumn{2}{c|}{ FACULD. } & \multicolumn{2}{c|}{ IF E CEFET } \\
\cline { 2 - 9 } & PÚB. & PRIV. & PÚB. & PRIV. & PÚB. & PRIV. & PÚB. & PRIV. \\
\hline $\mathbf{2 0 0 3}$ & 1.025 .269 & 1.293 .828 & 16.605 & 486.972 & 89.504 & 965.048 & 44.796 & 14.911 \\
\hline $\mathbf{2 0 0 7}$ & 1.176 .893 & 1.754 .224 & 17.617 & 688.025 & 106.53 & 1.472 .721 & 34.137 & - \\
\hline $\mathbf{2 0 1 1}$ & 1.541 .971 & 2.090 .402 & 14.898 & 906.121 & 114.82 & 1.969 .851 & 101.626 & - \\
\hline $\mathbf{2 0 1 5}$ & 1.663 .222 & 2.609 .933 & 18.844 & 1.338 .958 & 125.203 & 2.126 .261 & 144.876 & - \\
\hline $\boldsymbol{\Delta} \%$ & $62 \%$ & $101 \%$ & $13 \%$ & $174 \%$ & $40 \%$ & $120 \%$ & $223 \%$ & $-100 \%$ \\
\hline
\end{tabular}

Fonte: Instituto Nacional de Estudos e Pesquisas Anísio Teixeira - Sinopse e Estatísticas do Ensino Superior.

A Tabela 4 permite visualizar os diferentes tipos de organizações acadêmicas nas quais estão distribuídas as matrículas da educação superior no Brasil. No que se refere às universidades públicas no período de 2003 a 2015, o número de matrículas cresceu 62\%; as universidades privadas cresceram $101 \%$ e os Centros Universitários públicos cresceram 13\%. Neste tipo de instituição vai ocorrer o maior crescimento na rede privada com um crescimento de 174\% seguido pelas Faculdades Privadas (120\%). No setor público, o maior crescimento acontece na categoria Institutos Federais (IF) e nos Centros Federais de Educação Tecnológica recém-criados. Com um crescimento de $223 \%$, essa categoria na rede privada aparece, no ano de 2003, com uma matrícula de 14.911 alunos e se extingue nos outros anos. Os dados evidenciam a supremacia da rede privada no ensino superior e sua oferta em instituições como os Centros Universitários e Faculdades. Tais instituições de ensino, tradicionalmente, não priorizam a pesquisa (uma vez que sua oferta é mais dispendiosa), assim, as formações acadêmicas profissionalizantes e alijeiradas acabam por ser mais apelativas para os estudantes carenciados que através do Pro-Uni puderam ter acesso mais fácil ao ensino superior.

Foi determinante para a atual expansão da educação superior no Brasil, nomeadamente no segmento privado, o art. 45 da Lei de Diretrizes e Bases da Educação no 9.394 que determina que a oferta da educação superior seja suprida em Instituições públicas e/ou privadas em diversos níveis de abrangência. Esse artigo consolida o ensino nas instituições privadas, o que permitiu a expansão expressiva das matrículas nessa rede de ensino. É preciso considerar que a rede pública também teve uma expansão muito grande, mas, como já vinha sofrendo um grande déficit de atendimento, o seu crescimento ficou muito abaixo do da rede 
privada. $\mathrm{O}$ art $^{\mathrm{o}} 45$ foi regulamentado pelo Decreto $\mathrm{n}^{\mathrm{o}} 2.306 / 2007$ e, posteriormentealterado, pelo Decreto $\mathrm{n}^{\mathrm{o}}$ 3.860, do 9 de julho de 2001, que altera as regras de organização do ensino superior e da avaliação de cursos e instituições, e definiu nova mudança na diversificação das instituições de ensino superior.

\subsection{Os caminhos da expansão do ensino superior em Portugal, pós-Revolução de 1974}

A expansão do ensino superior em Portugal deu-se a partir de 1974 com o alvorecer da democracia renascida com a Revolução Democrática de 25 de Abril, a "Revolução dos Cravos". O processo de democratização iniciado com a Revolução explica a procura explosiva por educação no país, em todos os níveis educativos, bem ilustrada pela evolução das taxas reais de escolarização por nível de ensino. Observem-se os valores da Tabela 5:

Tabela 5 - Taxa bruta de escolarização por nível de ensino ${ }^{1}$

\begin{tabular}{c|c|c|c|c}
\hline Ano & $\begin{array}{c}\text { Educação Pré- } \\
\text { escolar }\end{array}$ & $\begin{array}{c}\text { Ensino } \\
\text { Básico }\end{array}$ & $\begin{array}{c}\text { Ensino } \\
\text { Secundário }\end{array}$ & Ensino Superior \\
\hline $\mathbf{1 9 6 1}$ & 1,2 & 70,2 & 2,8 & $\mathrm{X}$ \\
\hline $\mathbf{1 9 7 0}$ & 2,9 & 88,1 & 5,9 & $\mathrm{X}$ \\
\hline $\mathbf{1 9 8 0}$ & 15,4 & 100,4 & 32,8 & 10,7 \\
\hline $\mathbf{1 9 9 0}$ & 44,6 & 112,0 & 60,9 & 20,2 \\
\hline $\mathbf{2 0 0 0}$ & 73,3 & 122,1 & 105,4 & 48,8 \\
\hline $\mathbf{2 0 0 3}$ & 77,3 & 118,5 & 106,4 & 53,4 \\
\hline $\mathbf{2 0 0 7}$ & 78,5 & 118,0 & 102,3 & 56,7 \\
\hline $\mathbf{2 0 1 1}$ & 87,4 & 122,2 & 134,9 & 55,0 \\
\hline $\mathbf{2 0 1 5}$ & 90,9 & 110,3 & 117,4 & 50,2 \\
\hline $\mathbf{2 0 1 6}$ & 91,1 & 109,6 & 114,7 & 50,4 \\
\hline
\end{tabular}

Fontes/Entidades: DGEEC/MEd - MCTES | INE, PORDATA; Última atualização: 2016-08-22.

No caso do ensino superior, o comportamento da procura social de educação encontrase estreitamente ligado, por um lado, à percepção individual e coletiva de que a educação é o grande instrumento de ascensão social (CABRITO, 2002) numa leitura a que não será estranha, também, a percepção dos trabalhadores e do mercado acerca da relação que se estabelece entre níveis educativos, produtividade, rendimentos e salários (BECKER, 1964; SCHULTZ, 1961). Independentemente das razões dessa procura, a verdade é que ela aconteceu em um ritmo alucinante no país. Se, no início da década de 1970, o número de estudantes do ensino superior se aproximava dos 40.000, nos finais da década, já passava dos 80.000 e, em 2017,ultrapassava os 360.000 (PORDATA, acedido em 26/10/2017), sendo que, 
desde o final ${ }^{1}$ da década de 1990, a taxa real de escolarização no ensino superior ultrapassa os 20\%, caminhando para um ensino superior de massas (TROW, 1973).

Naturalmente, essa procura exigiu medidas de políticas educativas capazes de lhe dar respostas, que se concretizaram no incremento da oferta, seja por aumento do número de vagas nas universidades existentes, pela construção de novas universidades em meados da década de $1970^{2}$ e de institutos superiores politécnicos público, seja, finalmente, pela abertura deste nível educativo à inciativa privada ${ }^{3}$. De fato, em 1974, apenas havia funcionando 4 universidades públicas e prevista a criação de outras. Ao longo das décadas de 1970 e de 1980 novas instituições públicas iniciaram trabalhos ( 7 universidades, 1 instituto universitário e 15 institutos superiores politécnicos), bem como instituições privadas de ensino superior, tipo de ensino oficialmente criado em 1986.

Todavia, se é verdade que houve um enorme esforço por parte dos governos em disponibilizar vagas para os candidatos ao ensino superior, também é verdade que a procura continuou sempre a exceder a oferta, como se pode verificar, na Tabela 6 , pelo número de candidatos que foram excluídos do sistema.

Tabela 6 - Procura de Ensino Superior e resposta do sistema educativo, 1986-1993

\begin{tabular}{c|c|c|c}
\hline $\begin{array}{c}\text { Ano } \\
\text { letivo }\end{array}$ & $\begin{array}{c}\text { Número de candidatos } \\
\text { ao ensino superior }\end{array}$ & $\begin{array}{c}\text { Número de candidatos } \\
\text { que entraram no ensino } \\
\text { superior }\end{array}$ & $\begin{array}{c}\text { Número de } \\
\text { candidatos que não } \\
\text { entraram no ensino } \\
\text { superior }\end{array}$ \\
\hline $\mathbf{1 9 8 6 / 8 7}$ & 31.973 & 15.266 & 16.707 \\
\hline $\mathbf{1 9 8 8 / 8 9}$ & 37.625 & 19.233 & 18.392 \\
\hline $\mathbf{1 9 9 0 / 9 1}$ & 58.867 & 24.446 & 34.421 \\
\hline $\mathbf{1 9 9 2 / 9 3}$ & 59.166 & 28.751 & 30595 \\
\hline $\mathbf{\Delta \%}$ & $85 \%$ & $88 \%$ & $83 \%$ \\
\hline
\end{tabular}

Fonte: Ministério da Educação - Departamento do Ensino Superior.

Para equacionar esse problema, era de esperar uma dessas duas soluções: continuar a apostar no ensino superior público ou abrir o setor à iniciativa privada. Antes de mais nada, é preciso relembrar o que acima se referiu: até 1974, o ensino superior em Portugal era tradicionalmente público. As quatro (4) universidades existentes antes da Revolução eram públicas. Até essa data, no que respeita ao ensino privado, apenas existia a Universidade Católica ao abrigo da Concordata com a Santa Sé. Todavia, a dificuldade de ingresso dos

${ }^{1}$ Percentual de estudantes matriculados num determinado nível de ensino face à população em idade normal de frequência desse nível

Aliás, algumas já haviam sido criadas em 1973, mas só vieram a entrar em funcionamento depois de 1974.

Aliás, algumas já haviam sido criadas em 1973, mas só vieram a entrar em funcionamento depois de 1974

3 Anteriormente, além das universidades públicas, apenas existia a Universidade Católica criada em 13 de outubro de 1967 e reconhecida pelo Estado Português em 15 de julho de 1971, como pessoa coletiva de utilidade pública. 
candidatos nas universidades públicas e, mais tarde, também, nos institutos superiores politécnicos, criou um exército de candidatos de reserva ao ensino superior aptos a ingressar em qualquer instituição. Aproveitando essa falha do mercado educativo bem como alguma instabilidade política que dominou essas décadas, foram aparecendo pelo país instituições privadas que disponibilizavam educação de nível superior ainda que sem qualquer reconhecimento oficial. Na verdade, foram muitos os estudantes que fizeram estudos em IES privadas, cujo diploma não tinha qualquer valor no que concerne a concursos públicos. Já no quadro empresarial, o mercado começou a atribuir valor a esses diplomas, empregando esses egressos. Gradualmente, à medida que o mercado aceitava aqueles profissionais, o ensino superior privado tornou-se relevante e, para o capital, um setor de investimento altamente rentável uma vez que havia procura assegurada, multiplicando-se pelo país afora institutos superiores e universidades privadas de qualidade duvidosa, mas que respondiam às exigências do mercado. Tendo em vista a pressão pela procura e pela oferta, e a necessidade de normalizar o setor privado que ia crescendo, em 1986 o governo, encabeçado pela direita política portuguesa, expandiu o ensino superior à iniciativa privada.

Nessas circunstâncias, a expansão da educação superior foi garantida pelo setor privado, chegando a atender a um terço dos jovens matriculados. Observe-se a Tabela 7.

Tabela 7 - Número de matrículas no ensino superior, público e privado (número e \%)

\begin{tabular}{|c|c|c|c|c|c|}
\hline \multirow{2}{*}{ Anos } & \multicolumn{2}{|c|}{ Ensino Superior Público } & \multicolumn{2}{|c|}{ Ensino Superior Privado } & \multirow{2}{*}{ Total } \\
\hline & Número & $\%$ & Número & $\%$ & \\
\hline 1970 & 46.172 & 93,4 & 3.289 & 6,6 & 49.461 \\
\hline 1980 & 73.869 & 91,3 & 7.050 & 8,7 & 80.919 \\
\hline 1990 & 119.733 & 75,8 & 38.136 & 24,2 & 157.869 \\
\hline 2000 & 255.008 & 68,2 & 118.737 & 31,8 & 373.745 \\
\hline 2003 & 290.532 & 72,5 & 110.299 & 27,5 & 400.831 \\
\hline 2007 & 275.321 & 75,1 & 91.408 & 24,9 & 366.729 \\
\hline 2011 & 307.978 & 77,7 & 88.290 & 22,3 & 396.268 \\
\hline 2015 & 292.359 & 83,6 & 57.299 & 16,4 & 349.658 \\
\hline 2016 & 297.884 & 83,6 & 58.515 & 16,4 & 356.339 \\
\hline 2017 & 302.596 & 83,6 & 59.347 & 16,4 & 361.943 \\
\hline
\end{tabular}

Fontes/Entidades: DGEEC/MEd - MCTES, PORDATA; Última actualização: 2017-09-29.

A análise dos valores da tabela acima evidencia bem a forma como tem evoluído, no total e por subsistema, o número de matrículas e o papel que o ensino privado desempenhou no atendimento da procura. Desde a década de 1980, a procura de ensino superior cresceu em ritmo acelerado, tendo-se verificado uma desaceleração desse crescimento nos últimos anos, 
como resultado de um duplo conjunto de fatores. Por um lado, a diminuição das taxas de natalidade e de fertilidade já começa a se fazer sentir no acesso ao ensino superior; e, por outro, a crise financeira e as políticas de austeridade por que o país passou fundamentalmente após 2008. Os últimos valores, todavia, parecem revelar a inversão da tendência para a diminuição do número de matrículas sendo que o número de matrículas ainda pode crescer, por um lado pelo aumento do número de jovens que se candidatem ao ensino superior - uma vez que uma grande percentagem dos jovens ainda fica pela escolaridade obrigatória - e, por outro, pelo acesso de indivíduos adultos que não tiveram a possibilidade de aceder a esse nível de ensino na idade certa. Veja-se, entretanto, a evolução do número de matrículas no ensino superior privado: tendo conhecido um forte crescimento nas décadas de 1980 e 1990 foi, todavia, fortemente afetado pela crise que o país atravessou.

Uma circunstância que também tem vindo a caracterizar a procura de ensino superior em Portugal é a sua feminização para o que terá concorrido toda uma alteração da forma de olhar a mulher no período pós-Revolução. A procura pelos jovens do sexo feminino tem crescido mais do que a dos jovens do sexo masculino sendo que, atualmente, e excetuando-se alguns cursos tradicionalmente masculinizados, como alguns cursos de engenharia $(27,5 \%$ em Engenharia, Indústria e Construção e 44,2\% em Ciências, Matemática e Informática, em 2017, de acordo com PORDATA), as mulheres são predominantes. Observem-se os valores da Tabela 8 .

Tabela 8 - Matrículas por sexo, total do ensino superior (público e privado)

\begin{tabular}{r|r|r|r|r|r}
\hline \multirow{2}{*}{ Anos } & \multicolumn{2}{|c|}{ Masculino } & \multicolumn{2}{c|}{ Feminino } & \multirow{2}{*}{ Total } \\
\cline { 2 - 5 } & Número & \multicolumn{1}{c}{$\%$} & Número & \% & \multicolumn{1}{c}{81.582} \\
\hline $\mathbf{1 9 7 8}$ & 47.517 & 58,2 & 34.065 & 41,8 & 80.919 \\
\hline $\mathbf{1 9 8 0}$ & 45.370 & 56,1 & 35.549 & 43,9 & 157.869 \\
\hline $\mathbf{1 9 9 0}$ & 68.123 & 43,2 & 89.745 & 56,8 & 373.745 \\
\hline $\mathbf{2 0 0 0}$ & 162.524 & 43,5 & 211.221 & 56,5 & 400.831 \\
\hline $\mathbf{2 0 0 3}$ & 173.971 & 43,4 & 226.860 & 56,6 & 366.729 \\
\hline $\mathbf{2 0 0 7}$ & 168.821 & 46,0 & 197.908 & 54,0 & 396.268 \\
\hline $\mathbf{2 0 1 1}$ & 184.627 & 46,6 & 211.641 & 53,4 & 361.943 \\
\hline $\mathbf{2 0 1 7}$ & 167.919 & 46,4 & 194.024 & 53,6 & \\
\hline
\end{tabular}

Fontes/Entidades: DGEEC/MEd - MCTES, PORDATA; Última actualizacão: 2017-09-29.

Outra importante análise acerca do ensino superior de um país é aquela relacionada à própria estrutura da oferta. Em Portugal, até a década de 1970, apenas existia ensino superior universitário. Todavia, após a Revolução de Abril, e como forma de responder mais 
rapidamente à procura por educação superior, foi criado o ensino superior politécnico. Esta via educativa distinguia-se da via universitária fundamentalmente por oferecer uma formação mais próxima do mercado de trabalho. Em termos de diplomas concedidos, os institutos politécnicos ofereciam cursos de apenas 3 (três) anos, ao invés das universidades cujos cursos de formação inicial se estendiam por 5 (cinco) anos. Presentemente, e decorrente do Processo de Bolonha, esta diferença na duração da formação disponibilizada pelas duas vias de ensino superior deixou de existir. Universidades e institutos superiores politécnicos disponibilizam os $1^{\circ}$ e $2^{\circ}$ ciclos de ensino superior com igual duração, 3 e 2 anos, respectivamente a que correspondem os diplomas de "licenciatura" e de "mestrado". Todavia, mantêm-se diferenças significativas entre os dois subsistemas: a maior proximidade da formação dos institutos superiores politécnicos das necessidades do mercado de trabalho, por um lado e, por outro, a concessão de diploma de "doutor" apenas pelas universidades. Essas características das duas vias de ensino contribuem para explicar o mais baixo estatuto social dos institutos superiores politécnicos que são mais procurados pelos jovens, oriundos de estratos sociais menos favorecidos (CERDEIRA et al., 2017). Quer a via universitária quer a via politécnica ambas são disponibilizadas pelo ensino superior público e pelo ensino superior privado. $\mathrm{Na}$ Tabela 9 , vê-se a distribuição das matrículas no ensino superior por subsistema e tipo de ensino.

Tabela 9 - Matrículas no ensino superior universitário e politécnico, público e privado

\begin{tabular}{c|c|c|c|c|c|c|c}
\hline \multirow{2}{*}{ Anos } & \multirow{2}{*}{ Total } & \multicolumn{2}{|c|}{ Ensino Superior Público } & \multicolumn{2}{c}{ Ensino Superior Privado } \\
\cline { 3 - 8 } & & Total & Univ. & ISPolit. & Total & Univ. & ISPolit. \\
\hline $\mathbf{1 9 9 0}$ & 157.869 & 119.733 & 95.746 & 23.987 & 38.136 & 32.756 & 5.380 \\
\hline $\mathbf{2 0 0 0}$ & 373.745 & 255.008 & 164.722 & 90.286 & 118.737 & 88.190 & 30.547 \\
\hline $\mathbf{2 0 0 3}$ & 400.831 & 290.532 & 178.000 & 112.532 & 110.299 & 77.109 & 33.190 \\
\hline $\mathbf{2 0 0 7}$ & 366.729 & 275.321 & 169.449 & 105.872 & 91.408 & 60.659 & 30.749 \\
\hline $\mathbf{2 0 1 1}$ & 396.268 & 307.978 & 193.106 & 114.872 & 88.290 & 60.452 & 27.838 \\
\hline $\mathbf{2 0 1 5}$ & 349.658 & 292.359 & 191.707 & 100.652 & 57.299 & 42.666 & 14.633 \\
\hline $\mathbf{2 0 1 7}$ & 361.943 & 302.596 & 192.201 & 110.395 & 593.47 & 43.013 & 16.334 \\
\hline
\end{tabular}

Fontes/Entidades: DGEEC/MEd - MCTES, PORDATA; Última actualização: 2017-09-29.

Os valores da Tabela 9 são bem elucidativos do maior papel que o ensino superior público desempenha no atendimento dos jovens que buscam ensino superior, seja na via universitária, seja na politécnica. Não causam estranhezas as dificuldades financeiras vivenciadas pelas famílias portuguesas, a enorme diferença entre o montante das taxas de frequências cobradas pelas IES públicas e as IES privadas e a percepção da qualidade do ensino ministrado nos dois tipos de instituição, em detrimento do ensino superior privado. Por outro lado, verifica-se, também, o papel memorizado do ensino politécnico em face do ensino 
universitário, seja no ensino superior público, seja no ensino superior privado para o que poderá concorrer o diferente estatuto social atribuído aos dois tipos de instituição.

\section{Portugal/Brasil: algumas convergências e divergências no ensino superior}

A década de 1990 foi uma época de significativa expansão da educação superior em escala global, com fortes repercussões no Brasil e em Portugal. Isso ocorreu pela utilização de diferentes estratégias nos dois países como: ampliação do acesso pela via do crescimento do número de matrículas, do aumento e diversificação de cursos e de instituições, privatização do ensino e, particularmente no caso brasileiro, da utilização de novas modalidades como a educação a distância.

No Brasil, a aprovação da Lei de Diretrizes e Bases da Educação n 9.394/96 pode ser considerada o marco legal que normalizou a diversificação institucional e flexibilizou o atendimento por esse nível de ensino. Pode-se identificar, a partir da sua aprovação, a utilização de estratégias mercadológicas, o que permitiu a expansão da educação superior privada de forma desordenada e com repercussões para a qualidade da educação pela falta de mecanismos de regulação e controle.

Quanto a Portugal, a expansão da educação superior coincide com o processo de democratização do país, após a Revolução Democrática de 1974. A partir daí, percebe-se um crescimento explosivo da procura deste nível educativo cujo atendimento persegue, à semelhança do que se verifica no Brasil, objetivos mercadológicos, particularmente a partir de 1986 com as instituições privadas de ensino superior que, todavia, cresceram de forma ordenada após aquela data.

No que se refere ao número de vagas, no Brasil, tanto o setor público quanto o setor privado, tiveram um aumento substancial, ocorrendo o mesmo quanto ao número de vagas e ao número de candidatos inscritos. No entanto, quando se compara a relação vagas com candidatos inscritos, verifica-se uma expressiva concorrência por vagas no setor público. Isso pode ser explicado pela qualidade do ensino realizado nas universidades que priorizam o ensino, a pesquisa e a extensão; e pelo baixo poder aquisitivo da população que, mesmo com bolsas de estudos financiados pelo governo, faz opção pelo sistema público.

Em Portugal, o número de vagas do ensino superior privado cresceu de forma significativa, todavia, por razões diversas, nomeadamente pelo fato de os candidatos ao ensino superior público nem sempre conseguirem colocação no curso/IES que desejam. Outro fato é 
que todos os anos milhares de candidatos não conseguem ingressar nesse subsistema de ensino demandando, em consequência, uma vaga no ensino privado. Refira-se, todavia, que, atualmente, a rede pública consegue atender a todos os candidatos que a procuram pelo que, e contrariamente ao que se verifica no Brasil, em Portugal o atendimento à procura de ensino superior é garantido, fundamentalmente, pelas instituições públicas.

Em relação à distribuição das matrículas por sexo, o Brasil evidencia que a presença feminina é majoritária tanto na rede pública quanto na rede privada. Essa é, também, a realidade portuguesa. Em geral, o ensino superior em Portugal, feminilizou-se desde os finais do século passado. Importa, ainda, acrescentar que alguns domínios científicos, nomeadamente os que se relacionam com a educação e saúde, são marcadamente "femininos", enquanto domínios mais relacionados com as tecnologias continuam a ser fortemente "masculinos" reproduzindo, aliás, uma tradicional "divisão sexual do trabalho".

O Brasil tem consolidado, em seu sistema educacional superior, dois segmentos bem definidos e distintos: a) o sistema de educação público, garantido pela Constituição Federal em seu Art. 206, abrangendo um sistema complexo e diversificado de instituições públicas, distribuídas em três esferas do poder (federal, estadual e municipal); b) e o sistema privado, constituído por instituições particulares, comunitárias e/ou confessionais. A expansão da educação superior brasileira, no setor público, ocorre, principalmente nos Institutos Federais e nos Centros Federais de Educação Tecnológica e, posteriormente nas Universidades. No setor privado, ocorre o inverso: maior crescimento nos Centros Universitários e nas Faculdades, instituições mais voltadas para o ensino do que para a pesquisa.

Por seu turno, em Portugal, também já se encontram perfeitamente consolidados os setores público e privado do ensino superior, sendo que ambos os subsistemas disponibilizam ensino universitário e ensino politécnico. A expansão do ensino superior em Portugal ocorre, fundamentalmente, no ensino público destacando-se, todavia, as universidades.

Em termos de conclusão, é legítimo afirmar que o ensino superior, nos dois países, se feminilizou e registrou um forte e visível crescimento nas últimas décadas, acompanhando processos de democratização social, econômica e política ainda que esse crescimento se deva sobretudo ao setor privado, no Brasil, e ao setor público, em Portugal, orientado para políticas de expansão diferenciadas porque assentes em concepções diferentes do papel do Estado e do mercado no atendimento aos candidatos à educação superior. 


\section{Referências}

ALMEIDA, L; MARINHO-ARAÚJO, C; DIAS, D. Democratização do acesso e do sucesso no ensino superior: uma reflexão a partir das realidades de Portugal e do Brasil. Avaliação da educação superior. Campinas, 2012. vol. 17, n. 3, p. 899-920.

ALTHUSSER, L. Ideologia e aparelhos ideológicos de Estado. 3. ed. Lisboa: Editorial Presença/Martins Fontes, 1980.

BECKER, G. Human Capital - A Theoretical and Empirical Analysis, with Special Reference to Education. New York: Columbia University Press, 1964.

BRASIL, MEC. InepData - Consulta de Informações Educacionais. Número de matrículas em cursos de graduação por organização acadêmica e administrativa. Disponível em: http://inepdata.inep.gov.br/analytics/saw.dll?PortalGo. Acesso em: 08 jun. 2017.

BRASIL. Presidência da República. Lei $n^{\circ} 12.513$, de 26 de outubro de 2011. Dispõe sobre o Fundo de Financiamento ao Estudante do Ensino Superior. Disponível em: ww2.camara.leg.br/legin/fed/lei/2011/lei-12513-26-outubro-2011-611700-norma-pl.html. Acesso em: 23 ago. 2017.

BRASIL. Presidência da República. Decreto $n^{\circ} 5.800$, de 8 junho de 2006. Dispõe sobre o Sistema Universidade Aberta do Brasil. Disponível em: http://www.planalto.gov.br/ccivil_03/_ato2004-2006/2006/decreto/d5800.htm. Acesso em: 26 jul. 2017.

BRASIL. Presidência da República. Presidência da República. Casa Civil. Lei $N^{o} 11.096$, de 13 de janeiro de 2005. Institui o Programa Universidade para Todos - PROUNI, regula a atuação de entidades beneficentes de assistência social no ensino superior; altera a Lei $\mathrm{n}^{\circ}$ 10.891, de 9 de julho de 2004, e dá outras providências. Disponível em: http://www.planalto.gov.br/ccivil_03/_ato2004-2006/2005/lei/111096.htm. Acesso em: 26 jul. 2017.

BRASIL. Presidência da República. Casa Civil. Decreto $n^{\circ}$ 6.069, de 24 de abril de 2007. Institui o Programa de Apoio a Planos de Reestruturação e Expansão das Universidades Federais - REUNI. Disponível em: http://www.planalto.gov.br/ccivil_03/_ato20072010/2007/decreto/d6096.htm. Acesso em: 25 maio 2017.

BRASIL. Presidência da República. Casa Civil. Lei n 11.079, de 30 de dezembro de 2004. Institui normas gerais para licitação e contratação de parceria público-privada no âmbito da administração pública. Disponível em: http://www.planalto.gov.br/ccivil_03/_ato20042006/2004/lei/111079.htm. Acesso em: 25 maio 2017.

BRASIL. Presidência da República. Casa Civil. Subchefia para Assuntos Jurídicos. Lei $n^{\circ}$ 10.260, de 12 de julho de 2001. Dispõe sobre o Fundo de Financiamento ao estudante do Ensino Superior e dá outras providências. Disponível em: http://www.planalto.gov.br/ccivil_03/Leis/LEIS_2001/L10260.htm. Acesso em: 25 maio 2017. 
BRASIL. Presidência da República. Casa Civil. Lei nº 9.394 de 20 de dezembro de 1996. Estabelece as diretrizes e bases da educação nacional. Disponível em: http://www.planalto.gov.br/ccivil_03/Leis/19394.htm. Acesso em: 25 maio 2017.

CABRAL NETO, Antonio; CASTRO, Alda Maria Duarte Araújo. Educação Superior no Brasil: os contraditórios caminhos da expansao pós-LDB. 2014. In: I. Brezezinski (Org.) LDB/1996 Contemporanea: contradições, tensoes e compromissos. São Paulo: Cortez, p. 256285.

CABRITO, Belmiro Gil. Financiamento do Ensino Superior: Condição Social e Despesas de Educação dos Estudantes Universitários em Portugal. Lisboa: EDUCA, 2002.

CARNOY, M. El ajuste estructural y la evolución del mundo de la enseñanza. Revista Internacional del Trabajo. 1995. vol. 114, $\mathrm{n}^{\circ} 6$.

CASTELS, Manuel. A sociedade em rede: a era da informação: economia, sociedade e Cultura. Paz e Terra. 1999, vol 1, p. 87-164.

CERDEIRA, L.; CABRITO, B.; PATROCÍNIO, T.; MACHADO, M. L.; BRITES, R. Custos de Educação dos Estudantes do Ensino Superior Português. Lisboa: EDUCA, 2017 (no prelo).

CHAGAS LOPES, M. Educação, desenvolvimento e conhecimento: novas roupagens da troca desigual sob a globalização. O caso da África Subsahariana. In: Grandes Lições, 2013, vol. 2. Lisboa: Fundação Calouste Gulbenkian/Edições tinta-da-china.

INEP. Instituto Nacional de Estudos e Pesquisas Educacionais Anísio Teixeira. Sinopse Estatística da Educação Superior. (2003 a 2015). Disponível em: http://inep.gov.br/sinopsesestatisticas-da-educacao-superior. Acesso em: 19 jun. 2017.

MANCEBO, D. Reforma universitária: reflexões sobre a privatização e a mercantilização do conhecimento. In: Educação e Sociedade. 2004, vol. 25, n. 88, p. 845-866.

PORDATA - Base de Dados Portugal Contemporâneo. Disponível em: https://www.pordata.pt/Portugal. Acesso em: 26 out. 2017.

PORTUGAL. Legislação. Lei $n^{\circ}$ 62/2007. Dispõe sobre o Regime Jurídico das Instituições de Ensino Superior. Disponível em: http://data.dre.pt. Acesso em: 25 maio 2017.

SCHULTZ, Theodore W. Investment in Human Capital. In: American Economic Review. (1961). n. 51, p. 1-16.

SILVA JUNIÓR, J. R; CATANI, A. A Educação superior pública brasileira nas duas ultimas décadas: expansão e mercantilização internacionalizada. 2013. In: Vieira de Sousa (Org.). Educação superior: cenários, impasses e perspectivas. Campinas: Autores Associados.

TROW, Martin. Problems in the transition from elite to mass higher education. 1973. Carnegie Commission on Higher Education. 
UNESCO (2009). World Conference on Higher Education: The New Dynamics of Higher Education and Research for Societal Change and Development. Paris, 5-8 July 2009. UNESCO, Institute of Statistics. Disponível em: http://uis.unesco.org/. Acesso em: 25 maio 2017. 